\title{
LA FECUNDIDAD COMO FACTOR DEL CRECIMIENTO DEMOGRÁFICO: EL CASO DE LA POBLACIÓN VALENCIANA
}

\author{
Pedro Pérez Puchal
}

\begin{abstract}
Nunc hic nunc illic superant vitalia rerum et superantur item. Miscetur funere vagor quem pueri tollunt visentes luminis oras; noc nox ulla diem neque noctem aurora secutast quae non audierit mixtos vagitibus aegris ploratus mortis comites et funeris atri.
\end{abstract}

(Aqui y allí vence la vida y es vencida. Con los

llantos fúnebres se mezclan los que elevan los niños

al ver las riberas de la luz; ni una noche siguió al día, ni una aurora a la noche, que no oyera, entremezclados, los vagidos de los niños con los amargos lamentos, compañeros de la muerte y del negro funeral).

Lucrecio: De rerum natura, II, 575-580.

Ever love, ever the sobbing liquid of life, ever the bandage under the chin, evern the trestless of death. Walt Whitman: Leaves of Grass, «Song of Myself,» 42.

Nunca como ahora ha sido la natalidad tan decisiva en el crecimiento o decrecimiento de una población. Nunca tampoco como ahora ha estado tan amenazada la aparición de la vida y la renovación de las generaciones en el mundo occidental o influido por sus hombres y su cultura. Nunca, sin embargo, como en los años inmediatamente anteriores ha existido una explosión demográfica pareja a la experimentada en los llamados países en vías de desarrollo. [26]

\section{FECUNDIDAD Y CRECIMIENTO}

El crecimiento de una población está determinado por cuatro factores: nacimiento y defunciones, por una parte, cuya diferencia constituye el crecimiento vegetativo o natural, y el número de emigrantes e inmigrantes, por otra, cuyo saldo, positivo o negativo, da lugar a un aumento o disminución de los efectivos de población. En cuanto se trata de un Estado o país, es decir, de una masa considerable de gente, el crecimiento vegetativo suele ser el determinante o, al menos, el más importante en el crecimiento real o total, aunque haya excepciones temporales o bien en el caso de ciudades o de zonas de fuerte inmigración y crisis de natalidad. Lo que pasa es que la migración modifica en cierta medida la fecundidad, pues, donde se producen fuertes corrientes migratorias, normalmente entre zonas de diferentes niveles de natalidad, y dado el carácter selectivo del fenómeno migratorio, que mueve masas especialmente de jóvenes en edad reproductiva, tales corrientes determinan con frecuencia el rejuvenecimiento y reforzamiento de las fuerzas vitales 
de la población que las recibe o el debilitamiento de las mismas en la que pierde a sus jóvenes adultos; en definitiva, actúan por vía indirecta, pero muy eficiente, sobre el crecimiento natural. Este ha sido el caso de las regiones españolas (Pérez Puchal, 1980, 27 ss.) y el de las diversas comarcas valencianas, como vamos a ver.

Históricamente, la evolución de las poblaciones ha dependido fundamentalmente de las variaciones de la mortalidad, más pronunciadas que las fluctuaciones de la natalidad, también existentes. Ahora bien, como quiera que la mortalidad está descendiendo en todo el mundo y, en Europa, junto con otros países de cepa europea, se está llegando -se ha llegado ya en los más adelantados- al tope que prácticamente puede considerarse mínimo, porque por debajo de él no puede esperarse más descenso importante, y como, además, esa tendencia es irreversible, pues no cabe suponer que intencionadamente se aumente la mortalidad, es evidente que en estos países el factor decisivo por su caudal humano es la natalidad. Por el contrario, en el Tercer Mundo, es la baja de la mortalidad la que está determinando la explosión demográfica, pero, en el futuro, verosímilmente inmediato, conseguidas las metas sanitarias obtenidas en Europa y Norteamérica, es también notorio que de la fecundidad, asimismo, dependerá el crecimiento de su población.

En algunos países europeos, en efecto, la esperanza de vida al nacer o vida media está ya en los 75 y 76 años de edad y, de no descubrirse algún remedio contra las enfermedades degenerativas (ya que las ambientales están muy bien controladas), no cabe esperar cotas más bajas de mortalidad. En España, nuestra esperanza de vida al nacer, en la actualidad, [27] está en los 73'5 años y aún cabe esperar algún pequeño avance, sobre todo en el campo de la mortalidad infantil, pero poca cosa más. Con una mortalidad así de baja y, además, estable en lo que cabe suponer, es la natalidad la que marca el crecimiento vegetativo y, en el orden de las cifras nacionales, el crecimiento real, con las correcciones que impongan los saldos migratorios.

Y esa natalidad puede estar en unos niveles distintos, según el mayor o menor control que existe en los comportamientos matrimoniales y la mayor o menor generalización de esos usos en la sociedad. Por tanto, esa natalidad puede estar entre dos límites. El superior sería el de una natalidad totalmente incontrolada, meramente natural, lo que es sumamente improbable y más bien hipotético en aquellos países que tengan su mortalidad más o menos controlada; una fecundidad en esas condiciones daría, para una cohorte o promoción de mujeres de la misma edad y a lo largo de su vida procreativa, una media de siete a ocho hijos por mujer, dependiendo una u otra cifra de la proporción de mujeres solteras en edad reproductora y de la edad más frecuente de matrimoniar. A ese límite superior se aproximan bastante algunos países de Centroamérica, con mortalidad muy reducida y altísima natalidad. El límite inferior, de natalidad fuertemente controlada por todas las parejas, de modo que el número de hijos por pareja se aproximara muchísimo al deseado (y estos deseos cayeran muy por debajo), es evidente que no podría llegar a cero, ya que no puede presumirse que todos los matrimonios se negaran a tener descendencia; es inimaginable que se embotara hasta ese punto el instinto de propagación de la especie. Pero puede muy bien situarse en una media de poco menos de un hijo por mujer, dependiendo la cifra decimal del porcentaje de solteras y de esterilidades de ambos sexos, espontáneas o provocadas ${ }^{1}$. Un índice así, por debajo de 1, todavía no

\footnotetext{
${ }^{1}$ Las campañas en pro de la esterilización de padres y madres que tengan tres hijos, emprendidas en la India (Petersen, W., p. 353-5) y en la China (Aird. J., p. 177-193), cuyos efectivos humanos
} 
se ha registrado en ningún país, pues supone que todos los matrimonios se propusieran (y lo consiguieran) no tener más de un hijo. Pero es de notar que ya algunos países europeos (Alemania federal) han dado medias de 1'38 hijos, lo que demuestra que el ideal del Zweikindersystem (sistema de los dos hijos) que se propagó por la Europa noroccidental en el período de entreguerras está siendo reemplazado velozmente por el del Einzelkindsystem, un solo hijo por matrimonio. Esto en el campo de las realidades, a las que se aproximan mucho otros países vecinos o próximos, porque en el de las potencialidades, [28] en la China popular, dentro de la vacilante política demográfica aplicada por el Partido, la consigna de un solo hijo, dos a lo sumo, si el primero es niña, se ha dado insistentemente en los pasados años (Aird, J., pág. 171).

Para darse cuenta de lo que esto significa en orden al futuro de la población, conviene recurrir a los indices netos de reproducción o substitución o reemplazamiento, que marcan con bastante exactitud, bien que en el plano teórico, las posibilidades de que la generación vigente sea sustituida o reemplazada por la siguiente, igual o mayor, o, por el contrario, esa siguiente generación sea menor y en qué medida. Este índice señala, a partir de la descendencia media, el número de niñas (futuras madres, portadoras de la vida) que tendría una cohorte o promoción de mujeres (nacidas en el mismo año) en la hipótesis de que a lo largo de su vida procreativa mantuvieran los índices específicos de fecundidad por edades de ese año dado, una vez reducidos sus efectivos según las tablas de mortalidad por edades vigentes en ese año. Esto quiere decir que, en un país de fuerte mortalidad, bajará mucho el número de niñas antes de llegar a la edad reproductora y seguirá bajando durante la misma; por consiguiente habrá una notable diferencia entre el número total de hijos a que darán lugar y el que hubiera dado el total de nacidas de no haber sido diezmadas por la muerte, que es el que señala el índice bruto de la reproducción. Por el contrario, en un país de mortalidad muy baja, el índice neto de reproducción estará muy próximo al potencial o bruto. En otras palabras, en el índice neto se tiene en cuenta, para determinar la siguiente generación, no sólo la fecundidad, sino también la mortalidad y queda sólo como hipotético el que se mantenga inalterados los niveles específicos dados de fecundidad y de mortalidad por edades. De esta manera, un índice neto de sustitución de uno, o sea, de una hija por mujer de esta generación, que llegue a las edades procreativas y las supere supone una generación posterior igual en número a la anterior; mientras que un índice de más de uno o de menos marcará, respectivamente, una generación mayor o menor y en qué cuantía; v. gr. un índice 2 significa una generación doble y un índice de 0`90, una generación mermada en un 10 por 100 .

Aunque es un índice teórico, puesto que está sometido a la doble hipótesis, que nunca se darán con exactitud, de que esa cohorte de mujeres mantenga a lo largo de su vida hasta los 50 años los mismos índices de fecundidad y de mortalidad por edades que los de las tablas de que se parte, es lo cierto que marca con precisión las posibilidades de crecimiento natural de una población y las consecuencias en el caso de que fecundidad y mortalidad específicas por edades se modificaran en un sentido o en otro. [29]

Y como es, justamente, el problema del crecimiento o, más bien, del posible decrecimiento el que ha empezado a preocupar en los países desarrollados, donde

comprenden más de un tercio de la población mundial, hacen temer la generalización de esas prácticas por un mundo progresivamente amoralizado. 
mortalidad y natalidad están ampliamente controladas, a estos índices hay que atenerse, sin omitir por ello las alusiones que sean necesarias a los índices brutos de natalidad en comparación con los de mortalidad, los cuales relacionan el número anual de nacimientos y de defunciones con el total de la población media del mismo año y cuya comparación señala el crecimiento vegetativo efectivo en el año de que se trata, pero que son engañosos respecto a un futuro no demasiado lejano, porque ignoran el hecho real de que una parte de los nacidos fallecerá antes de llegar o de completar su período reproductivo. En efecto, cuando en la etapa de entreguerras la natalidad europea bajó a niveles del 19 por 1.000 y menos, muchos se tranquilizaban, como se tranquilizan ahora en que la natalidad se ha puesto en menos del 15 por 1.000 , pensando que, mientras los índices brutos de mortalidad se mantuvieran inferiores, en el peor de los casos, iguales no habría peligro de descenso de población; a muchos, incluso, les parecía y parece que un llamado crecimiento cero era y es deseable. La tasa neta de reproducción vino a dar un giro a esta visión irracionalmente optimista y Kuczynski, que fue el que la puso en circulación, pudo decir: Vuestros excedentes de nacimientos no son más que un espejismo y vuestras generaciones ya no aseguran su reemplazamiento. Y es que, siendo entonces la mortalidad más elevada que ahora, aunque la natalidad también lo era, los índices netos de reproducción habían caído por debajo de uno en varios países, llegándose en la Alemania prenazi al de 0 '7, lo que significa teóricamente una generación posterior mermada en un treinta por ciento respecto de la anterior. Eso sucedía cuando la descendencia final era de dos hijos por mujer, lo que venía a corresponder casi con el ideal de los dos hijos por matrimonio a que se ha hecho antes referencia y que era el que se estaba extendiendo por Europa y Norteamérica desde principios del siglo XX. Pues bien, en los años 70, con una mortalidad considerablemente más baja, pero que no podrá bajar apenas más, la natalidad ha descendido tanto, que en la Alemania federal se ha llegado en 1978 a un índice neto de reproducción de 0'65 (1'38 hijos por mujer). O sea que, aunque su crecimiento vegetativo, según los índices brutos de natalidad y mortalidad quedan muy próximos pero por encima de cero, lo cierto es que la generación siguiente, de mantenerse la misma natalidad, será un 35 por 100 menor que la de sus progenitores. La llamada de mano de obra extranjera en los años de la prosperidad económica, que se calcula en 2'3 millones de trabajadores entre 1960 y 1973, demuestra que Kuczynski tenía razón y que el fenómeno [30] no es de ahora, sino que viene desde los años veinte, efectos bélicos aparte.

Índices semejantes o muy aproximados se dan en Austria, Alemania oriental y Suiza, así como en casi todos los países escandinavos. El ideal del Einzelkindsystem, de un solo hijo, es patente en la Europa germánica. El resto de la Europa occidental tampoco queda lejos de esta situación. ¿Qué bárbaros sustituirán a los bárbaros germanos que, a su vez, sustituyeron a los civilizadísimos y no bastante fecundos romanos?

Por otra parte, hay que manejar también los índices brutos de natalidad, ya que, respecto a las provincias valencianas, objeto preferente de este estudio, no contamos con muchos datos anteriores o posteriores a 1975 para obtener la descendencia final y las tasas de reproducción. Sobre los índices brutos, baste decir que los correspondientes a países subdesarrollados de alta natalidad son superiores al 30 por 1.000 (e incluso al 40 en África negra). Los índices que están entre el 20 y el 30 por 1.000 se dan en países que están evolucionando decididamente en el control de nacimientos, como sucede en Cuba, por ejemplo, y, los que controlan generalizadamente la natalidad, los tienen inferiores al 20 por 1.000 , como sucede 
con la generalidad de los países europeos, los extraeuropeos de cepa anglosajona y el Japón. Lo que sucede es que, a partir de finales de los años sesenta, algunos países europeos han bajado sus índices del 15 por 1.000, lo cual empieza a situarlos en tasas de reproducción neta de menos de uno. Y es más, como quiera que las poblaciones de baja natalidad sostenida a lo largo de muchos años, como ocurre en Europa, van envejeciendo progresivamente, es decir, la proporción de viejos va aumentando, es claro que los índices brutos de mortalidad van subiendo en la misma proporción, de suerte que están empezando a encontrarse con los de la natalidad bruta en los niveles del 11 al 14 por 1.000 , con lo que se llega al decrecimiento vegetativo año por año. Tal ha sido el caso de Austria en 1978.

\section{LA EVOLUCIÓN ESPAÑOLA}

Por lo que se refiere a España, ha seguido con un poco de retraso el mismo camino que los demás países europeos al norte de los Pirineos. Es decir, descenso paulatino de natalidad y mortalidad, lentísimo en la última mitad o, mejor, en el último tercio del pasado siglo, más y progresivamente acelerado en nuestro siglo y siempre con alguna ventaja en ritmos y cuantía para la mortalidad. La baja de ésta precede siempre a la de la natalidad. Sólo que a los niveles que otros países alcanzan hacia los años veinte, por ejemplo, nosotros llegamos, por mortalidad, en los cuarenta y, por nacimientos, hacia 1970. En los últimos decenios del pasado [31] siglo, los niveles de ambas son todavía muy altos, por encima del 30 por 1.000 , y la diferencia entre una y otra es pequeña, oscilando en torno al 0'5 por 100, que es el crecimiento vegetativo. Este, sin embargo, es superior al crecimiento real, que fue del 0’3 por 100 anual acumulativo, por tratarse España de un país de emigración neta, es decir, por superar los emigrantes sobre los inmigrantes. Pasado el tiempo, en 1923, entra decididamente España en la fase intermedia tanto en natalidad como en mortalidad, al situarse los índices brutos respectivos por debajo del 30 y del 20 por 1.000, pero mientras esta última hace el tránsito rápidamente y en el año 1947 traspasa el 12 por 1.000 para bajar en seguida al 10'8 por 1.000 en 1950, aquella, la natalidad, tardará 46 años en hacerlo y sólo bajará del 20 por 1.000 en 1969, fecha en la que hay que fijar la extensión plenamente generalizada entre matrimonios del control de nacimientos. Esta evolución someramente descrita significa que nuestra explosión demográfica que en todos los pueblos corresponde a un cierto momento de esa fase de transición demográfica entre una mortalidad y una natalidad poco o nada restringidas a otras mucho más bajas y controladas, en mayor o menor medida, pero con carácter general, se da igualmente entre nosotros, aunque bastante atenuada, en el medio siglo que va de 1920 a 1970 , durante el cual el crecimiento vegetativo sube por encima del 1 por 100 , con alguna oscilación debida a la guerra civil y a los delicados años cuarenta. Bien que, al seguir siendo España proveedor de emigrantes a otros países, el crecimiento real se mantiene un poco por debajo del 1 por 100 acumulativo. Lo suficiente, sin embargo, para que la población nacional se haya duplicado en los últimos ochenta años. El mayor crecimiento se da a partir de 1956 en que, mientras la mortalidad sigue descendiendo, la natalidad comienza a elevarse y permanece en un $21^{\prime} 5$ por 1.000 hasta 1965 , en que reanuda el descenso.

Ahora bien, a partir de 1970 el descenso de natalidad continúa con mucha lentitud, de modo que el índice bruto se encontraba en dicho año a la altura del 19'6 por $1.000 \mathrm{y}$, en 1975 , se halla en el 19 por 1.000 . Pero, a partir de esta fecha, el descenso se acelera, cada año pierde aproximadamente un punto y, en 1980, última 
cifra de la que se dispone, aunque no enteramente segura, está en el 15’2 por 1.000, o sea, ese límite por debajo del cual se enciende la luz roja de aviso sobre el mantenimiento de la población en nuestras condiciones de mortalidad. En el mismo decenio, ésta baja ligeramente del 8'5 al 7'7 por 1.000 , lo que, en una población que está envejeciendo progresivamente indica con claridad que la mortalidad real (independiente de la composición por edades) ha seguido descendiendo y así lo confirma la baja de la mortalidad infantil de 21 a 13 defunciones de menores de un año por cada mil nacidos. [32] Por eso, el quinquenio 1975-1980 se distingue por la caída del aumento vegetativo por debajo del 1 por 100 anual, pero también por otro rasgo, y es que, durante el mismo, el saldo migratorio se ha vuelto positivo, o sea, que entran más de los que salen. El crecimiento real de la población, pues, sería superior al vegetativo.

Por lo que respecta a la descendencia final, que en 1900 era de 4'71 hijos por mujer, bajó a 4 en 1920, a 3 en 1940, a 2'5 en 1950, para volver a subir a 2'8 en 1960 y 2'9 en 1970, pero bajó a 2'77 en 1975 y, según parece, porque no hay cifras seguras publicadas todavía, en 1980 se ha puesto en 2'16 hijos por mujer, lo que, dada la mortalidad por edades actual supone un índice neto de reproducción de 1. Es de notar que, en relación a la mortalidad del pasado, los índices netos de reproducción durante el siglo XX han estado siempre entre el 1'2 y 1'3 y sólo en 1950 se aproximó a 1'0. En el caso de confirmarse la cifra mencionada para 1980, si el descenso de la natalidad continúa, para 1981 o 1982 tendríamos ya una reproducción neta inferior a 1 .

Digamos, sin embargo, que estas cifras últimas hay que ponerlas entre paréntesis hasta que se confirmen con las cifras completas del Censo y del Movimiento natural de 1981. Por otro lado, el descenso del último quinquenio, tanto en cifras brutas como en descendencia final, se explica en una pequeña parte por el efecto «eco» demográfico, o sea, la llegada en 1975 a la edad de máxima reproducción de las promociones o cohortes nacidas en torno a 1950 y recortadas por la baja natalidad de aquella época; de modo que cuando a partir de 1985 lleguen a análogas edades las cohortes nacidas en torno a 1960, coeteris paribus, la natalidad tendría que subir. Pero es dudoso que las demás cosas, y entre ellas la fecundidad, sigan iguales. También ha influido últimamente el descenso de la nupcialidad causado por la crisis económica. En efecto, durante el último siglo transcurrido, los índices de nupcialidad se han mantenido constantes, oscilando entre 7 y 8 matrimonios por cada 1.000 habitantes, sin más excepciones que la de los años treinta, también de crisis y, además, de guerra civil y alguna otra esporádica y aislada. Pues bien, en 1980, el índice expresado, que aún se mantenía en niveles normales en 1977, parece que ha caído súbitamente al 5’7 por 1.000, de confirmarse las cifras provisionales.

\section{EL CASO VALENCIANO}

La evolución de la región valenciana es similar a la general de España, sólo que más rápida y anticipada, debido a que las costumbres contraconceptivas, que penetran en España por Cataluña y Baleares poco más o menos con el siglo, se extienden pronto a las provincias valencianas, [33] antes de propagarse al resto de España. En esta anticipación de las costumbres matrimoniales tienen probablemente mucho que ver el mayor contacto con la sociedad europea, el superior nivel de vida, la distribución menos desigual de la renta, la mayor participación de la mujer en el 
trabajo industrial y de servicios, atraída por los puestos de empleo que va creando el incipiente desarrollo económico de los comienzos de nuestro siglo $\mathrm{y}$, en general, todas las circunstancias y actitudes que origina lo que los sociólogos llaman modernización (Brown, Sánchez Albornoz, passim), que no se confunde con la urbanización y la industrialización (aunque no las excluya), sino más bien con la educación e instrucción, los intercambios comerciales con el extranjero, la cantidad y tipo de información que va calando en los estratos sociales y estimula a los individuos y les da confianza para asumir la dirección de su propio destino y el de sus familias y, en fin, los cambios profundos en las ideas y valores sociales. No hay muchas dudas sobre la existencia de ese foco de modernización, así entendida, en Cataluña y Baleares a través de las relaciones comerciales, culturales y turísticas, especialmente con Francia, y de Cataluña se difunde a Valencia, y directamente también a través del comercio de exportación.

Además en Valencia hay un adelanto en el declive de la mortalidad que, asimismo, precede al de la natalidad. En efecto, es ya más baja que la general del conjunto español en 1900 y, en los años iniciales del segundo decenio, entra en la fase que podemos llamar Intermedia (inferior al 20 por 1.000), con la única excepción del año 1918, a causa de la mortífera epidemia de gripe. Lo mismo sucede con la natalidad que, casi al nivel general español en 1900, baja del 30 por 1.000 en los mismos años. Esa fase intermedia, iniciada en Valencia con más de diez años de antelación, es de mucho más rápido transcurso en la natalidad, pues cruza la frontera del 20 por 1.000 , definidora de la natalidad débil y controlada, a comienzos de los años cuarenta, mientras en la generalidad de España no se traspasa ese límite hasta 1969. La transición de la fase intermedia en la mortalidad, en cambio, al estar condicionada al progreso científico y sanitario (sulfamidas, antibióticos principalmente), es más acomodada a la general española, ya que se desciende del 12 por 1.000 (límite de la mortalidad controlada en una población no muy joven) en la segunda mitad del decenio de los 40 . Bien es verdad que el mayor envejecimiento de la población valenciana, producido por una menor natalidad sostenida, explica un cierto retardo en el descenso del índice bruto, que no se corresponde con una sanidad real diferencial, según se trasparece en una mortalidad infantil menor que la general de España. Es esa mayor vejez de la población lo que mantiene a los índices brutos de mortalidad más altos desde 1950 que los generales de España. [34]

En resumen, que la transición demográfica se completó antes por haberse adelantado su comienzo; que el descenso de ambas variables ha sido más acompasado y coincidentes en el tiempo su entrada en los niveles bajos de una y otra $\mathrm{y}$, por tanto, su crecimiento vegetativo, muy moderado y por debajo del 1 por 100 anual, no ha dado lugar a una verdadera explosión demográfica, por lo menos hasta que, a partir de 1957, el aumento masivo de la inmigración modifica todas las circunstancias. Ese aumento vegetativo tan pausado explica que el crecimiento real, un poco superior, tuviera un ritmo más lento (0'74 por 100 anual acumulativo) que en la totalidad de España (0’84 por 100) entre 1900 y 1960.

Desde el punto de vista de la fecundidad se aprecia mejor ese menor aumento natural. Véase, si no, la siguiente tabla. 


\begin{tabular}{|c|c|c|c|c|c|c|c|c|c|c|}
\hline \multirow[b]{2}{*}{$\underline{A \tilde{n} O}$} & \multicolumn{6}{|c|}{ Región } & \multicolumn{2}{|c|}{ Castellón } & \multicolumn{2}{|c|}{ Valencia } \\
\hline & $\begin{array}{r}\text { Desc } \\
\text { final }\end{array}$ & $\begin{array}{l}\text { Repr. } \\
\text { neta }\end{array}$ & $\begin{array}{l}\text { Desc. } \\
\text { final }\end{array}$ & $\begin{array}{l}\text { Repr } \\
\text { neta }\end{array}$ & $\begin{array}{r}\text { Desc } \\
\text { final }\end{array}$ & $\begin{array}{l}\text { Repr } \\
\text { neta }\end{array}$ & $\begin{array}{l}\text { Desc. } \\
\text { final }\end{array}$ & $\begin{array}{c}\text { Repr. } \\
\text { neta }\end{array}$ & $\begin{array}{l}\text { Desc. } \\
\text { final }\end{array}$ & $\begin{array}{l}\text { Repr. } \\
\text { neta }\end{array}$ \\
\hline 1922 & & 1'21 & 3'56 & $1 ' 05$ & 3'51 & $1 ' 03$ & 3'71 & 1'09 & $3 ' 50$ & $1^{\prime} 03$ \\
\hline & 63 & 1'29 & 3'05 & $1^{\prime} 08$ & 3'15 & $1 ' 12$ & $2 ’ 87$ & $1 ' 02$ & 2'96 & $1^{\prime} 05$ \\
\hline 1 & 26 & 1'18 & $2 ’ 55$ & 0’93 & 2'88 & $1 ' 04$ & $2^{\prime} 38$ & $0 ’ 86$ & $2^{\prime} 38$ & $0 ` 86$ \\
\hline 1945 & $2 ’ 86$ & 1'13 & $2^{\prime} 28$ & 0’90 & $2^{\prime} 53$ & $1 ' 00$ & 2’13 & $0 ’ 84$ & 2'10 & $0 ’ 83$ \\
\hline 1950 & $2^{\prime} 46$ & 1'04 & 2'11 & 0'89 & $2^{\prime} 28$ & 0’96 & $2^{\prime} 04$ & 0’86 & $2^{\prime} 01$ & $0 ’ 85$ \\
\hline
\end{tabular}

Fuente: De los índices netos de reproducción, Instituto Nacional de Estadística: Tasas netas de reproducción, Madrid, 1966.

La tabla de descendencia final señala la inferior fecundidad valenciana en ese medio siglo, bien que la diferencia se acorte en 1950. La de reproducción neta explica muy bien que el crecimiento de la población valenciana debe muy poco o nada a sus propias fuerzas generativas y mucho, en cambio, a la inmigración. Hasta 1930, el juego de natalidad y mortalidad apenas permite la sustitución de una generación por otra; de 1935 a 1950, ni siquiera eso. Conviene, sin embargo, distinguir entre las tres provincias, puesto que cada una presenta una evolución algo distinta. Mientras que Alicante, desde principios de siglo, tiene una natalidad inferior a la de sus provincias hermanas (apéndice I) y la de Valencia presenta la máxima provincial dentro de la región, hacia 1920 la fecundidad de las tres se iguala sensiblemente para pasar en seguida la de Alicante, aún dentro de la tónica descendente, a ostentar la tasa máxima, que ya no abandonará hasta la misma actualidad y llegará en 1960 a ser incluso superior a la media de España. Entre tanto, y dentro siempre del descenso continuado, Castellón sigue con una fecundidad semejante o un poco [35] superior a la de Valencia hasta que en 1960 pase a ser la última, situación en la que permanece.

Es decir, que el descenso paulatino de fecundidad en las tres provincias se hace más lento en la de Alicante, debido a que durante los dos primeros decenios la provincia alicantina tuvo una considerable emigración al extranjero, especialmente a América y norte de África, hasta que en el tercer decenio cesa la emigración y el saldo migratorio se vuelve positivo, con el consiguiente rejuvenecimiento de la población que esto comporta. Y su consecuencia, que es la activación de la fecundidad.

A finales del decenio de los cincuenta, la tendencia en la región se invierte, la natalidad se recupera y se produce a manera de un rellano hasta que, en 1975, la natalidad se hunda nuevamente, como en la generalidad española. Los índices brutos promedio de 1960-1965 se sitúan en 19'6 por 1.000 en Castellón, 19'9 en Valencia y 21 '9 en Alicante, cuando el índice general de España es de 21'3 para el quinquenio, nivel inferior al de Alicante. La evolución de la fecundidad a partir de los últimos años cincuenta es, como en España, de inversión de la curva de descenso, como se ve en la tabla siguiente.

\section{CUADRO II}




\begin{tabular}{|c|c|c|c|c|c|}
\hline Año & España & $\begin{array}{c}\text { Región } \\
\text { valenciana }\end{array}$ & Alicante & Castellón & Valencia \\
\hline & $\begin{array}{l}\text { Desc. Repr. } \\
\text { final neta }\end{array}$ & $\begin{array}{l}\text { Desc. Repr. } \\
\text { final neta }\end{array}$ & $\begin{array}{l}\text { Desc. Repr. } \\
\text { final neta }\end{array}$ & $\begin{array}{l}\text { Desc. Repr. } \\
\text { final neta }\end{array}$ & $\begin{array}{l}\text { Desc. Repr. } \\
\text { final neta }\end{array}$ \\
\hline 1960 & $2 ’ 76 \quad \overline{1 ’ 28}$ & $-\quad-$ & $-\quad-$ & $-\quad-$ & $-\quad-$ \\
\hline 1965 & $-\quad-$ & $1 ' 31$ & 2'99 1'39 & 2’44 & $2^{\prime} 68$ \\
\hline $1975-6$ & 2’77 1'30 & $1 ’ 38$ & 3'14 1'48 & 1'28 & $2 ’ 86$ \\
\hline
\end{tabular}

Fuente: De los correspondientes a 1965, calculados a partir de los índices de reprod. neta publicados por Nadal, Jordi: La población española (s. XVI a XX). Barcelona, Ariel, 1976, 4ª ed., pp. 239-240.

De aquí, pues, el aumento vegetativo creciente, producido y alimentado constantemente por una inmigración cada vez mayor, que rejuvenece a una población harto envejecida por la baja natalidad sostenida durante tantos años y cuyo rejuvenecimiento la hace más fecunda, al tiempo que fuerza a descender un poco los índices brutos de mortalidad, notoriamente mayores antes que los de la totalidad española. De esa manera, el crecimiento vegetativo está, durante esos quince años, en torno al 1 por 100 anual, en tanto que el real es del 2'16 por 100 anual acumulativo en el decenio de los sesenta y de 1'90 en el primer quinquenio de los setenta, pero con un máximo del 2'59 y 2'88, respectivamente, en la provincia de Alicante (cuyo saldo vegetativo es de 1'2 por 100) y un mínimo del 1'29 y 1'28 en Castellón que, evidentemente, atrae [36] muchos menos inmigrantes, y cuyo aumento natural es del 0'6 por 100 anual.

\section{CUADRO III \\ CRECIMIENTO ANUAL ACUMULATIVO DE LA POBLACIÓN (EN \%)}

\begin{tabular}{|c|c|c|c|c|}
\hline Territorio & $\underline{1900-1960}$ & $\underline{1961-1970}$ & $\underline{1971-1975}$ & $\underline{1976-1981}$ \\
\hline España & $0 ’ 84$ & 1'07 & $1 ’ 13$ & $0 ’ 79$ \\
\hline Región valenciana & $0 ’ 74$ & $2 ’ 16$ & $1 ' 90$ & $1 ’ 49$ \\
\hline Alicante & 0’69 & $2 ’ 59$ & $2^{\prime} 88$ & $1^{\prime} 81$ \\
\hline Castellón & $0 ’ 14$ & $1 ' 29$ & $1^{\prime} 28$ & $0 ’ 95$ \\
\hline Valencia & 0’96 & 2'14 & $1 ' 87$ & $1 ’ 23$ \\
\hline
\end{tabular}

En este Cuadro III se aprecia la aceleración del crecimiento real en los años sesenta, el mayor nunca experimentado por nuestra región, que ganó en esos diez años casi 600.000 almas, el 57 por 100 de las cuales en la provincia de Valencia, el 35 en la de Alicante y sólo el 8 por 100 en la de Castellón. Y es que esta última provincia se convierte en zona de emigración preponderante y únicamente la comarca de La Plana atrae fuerte inmigración que contrapesa el vaciamiento del interior montañoso, en tanto que el resto de la costa mantiene sus efectivos a duras penas. Solamente con la entrada en La Plana consigue la provincia incrementar el ritmo de aumento, pero siempre en mucho menor nivel que las otras dos provincias, de las cuales Valencia gana el mayor número de habitantes en cifras absolutas, pero 
la cadencia superior se da en Alicante y se seguirá dando en el decenio siguiente, siendo incluso la única que acelera el ritmo durante el quinquenio posterior. Porque, en efecto, entre 1970 y 1975 el ritmo desciende en Valencia y Castellón, aun manteniéndose en cotas más altas que la general de España y es en el segundo quinquenio cuando, a causa de la crisis económica, el compás desciende en las tres demarcaciones y, en Castellón, baja del 1 por 100 anual, aunque todavía resulte por encima del crecimiento vegetativo, lo que demuestra que La Plana sigue atrayendo fuerza de trabajo, aunque con menor intensidad. Con todo y con eso, la región aumentó entre 1960 y 1981 desde 2.481 .000 habitantes a 3.650.000 y más de las tres quintas partes de esos 1.160.000 son evidentemente inmigrantes que acudieron fundamentalmente a la oferta de empleo que brindaban los sectores de la construcción, estimulada por la rápida extensión urbana, de la industria fabril y de los servicios que se desarrollan velozmente entre el Plan de Estabilización de 1959 y 1974, fecha del inicio de la crisis mundial.

Una tal inyección de sangre joven y de ambos sexos no podía por menos que renovar la natalidad que venía en permanente descenso desde [37] finales del siglo XIX y había llegado a su mínimo en 1950 y en los años anteriores y posteriores inmediatos, con índices brutos de natalidad y tasas de fecundidad notoriamente inferiores a los generales de España. Pues bien, en 1960, estos índices siguen inferiores en las tres provincias a los generales, pero la distancia se ha acortado notablemente y, a partir de 1965, son ya decididamente superiores a los globales españoles, con la excepción de Castellón, a la que la sangría constante de la emigración de su interior no permite remontar mucho su fecundidad, salvo en La Plana, que en esto se comporta como la provincia de Valencia. En 1975, la natalidad se ha incrementado todavía más. El mapa de la fecundidad y de la mortalidad se configura desde 1960 con una diferencia provincial clara entre un norte (Castellón) de baja natalidad y mortalidad alta (relativamente), debido al envejecimiento de su población (56 viejos de más de 64 años por 100 jóvenes de menos de 15 años); un centro (Valencia) con fecundidad y mortalidad intermedias y menor envejecimiento (39 viejos por 100 jóvenes); y un sur (Alicante) con fecundidad alta y mortalidad baja por su población relativamente joven (36 viejos por 100 jóvenes), a causa de la mayor inmigración en proporción a su número de habitantes. (Pérez Puchal, 1980, p. 59-60). Por consiguiente, un incremento vegetativo que crece, asimismo, de norte a sur.

Después de 1975, la natalidad, como en todo el territorio español, ha reemprendido su camino en declive y, al parecer, puede estar en el 16 por 1.000 en 1981, un poco superior aún al general, pero, por supuesto a confirmar como éste, ya que resultan demasiado bajos.

En las diferencias provinciales respecto a la fecundidad no sólo juega el mayor o menor rejuvenecimiento ocasionado por la inmigración, mayoritariamente de adultos jóvenes, aunque éste sea el factor principal. Parece que hay también una cierta correlación entre natalidad y grado de instrucción, debida a que las prácticas anticonceptivas están menos difundidas o tienen menos éxito entre las personas de menos instrucción, de acuerdo con el esquema o modelo de que estas costumbres penetran en una sociedad por las clases más altas y se difunden rápidamente por las medias, esto es, por las clases que, normalmente, son las más cultas; finalmente, se filtran hacia la base de la pirámide social y se extienden por las clases más modestas, quedando los últimos los menos instruidos, ya que, tanto la abstinencia periódica, como la utilización de medio mecánicos o químicos exigen unos conocimientos, 
producen unas molestias y reclaman una persistencia que sólo desde un nivel de educación y formación intelectiva puede ser eficaz. Según la Encuesta sobre fecundidad practicada por el Inst. Nacional de Estadística en 1977, un 20\% de las mujeres analfabetas no conocen medio anticonceptivo alguno y en la misma situación se encuentra el $13 \%$ de las que [38] no tienen estudios primarios completos; y mientras que analfabetas y sin instrucción primaria, aunque sepan leer y escribir, declaran en un 50\% no haber utilizado nunca medios anticonceptivos, sólo un $16 \%$ de las que tienen estudios superiores declaran análogamente. Pues bien, atendiendo a las mujeres entre los 15 y los 34 años en 1975, resulta según el Censo que las analfabetas más las que no han recibido enseñanza primaria completa suman, en Castellón, el 28\% de las mujeres de la misma edad; en Valencia, el 29\% y, en Alicante, el 39\%. La inmigración menos intensa en Castellón y proporcionalmente más alta en Alicante puede ayudar a explicar también estas desigualdades en los niveles de instrucción. Pero queda en pie ese cierto grado de correlación entre fecundidad y niveles de instrucción.

\section{NATALIDAD, MORTALIDAD Y MIGRACIÓN EN LAS COMARCAS VALENCIANAS}

Cada provincia presenta, a su vez, como hemos visto de pasada en Castellón, diferencias muy notables en cuanto a natalidad y que, en síntesis, puede contraponer la faja costera con el interior montañoso, de orografía media, pero áspera, en Castellón y Valencia; en Alicante, en cambio, la contraposición es entre la zona litoral, valles y hoyas del interior, por una parte, y las montañas de la Marina y de las Serranías alcoyanas, de otra. Y es que la montaña, como en toda Europa ocurre, se despuebla de adultos jóvenes y la fecundidad de las poblaciones residentes decae. Son los movimientos migratorios los que definen hoy las diferencias vegetativas.

Ahora bien, de la comparación de los crecimientos (o decrecimientos) naturales con los reales (Apéndice II) resultan ser comarcas de fuerte emigración ${ }^{2}$ las siguientes:

a) Todas las de Castellón, salvo la Plana y parte de sus aledañas, el Alcalatén y el pla de l'Arc, así como la de Vinaroz-Benicarló.

b) En la provincia de Valencia, El Rincón de Ademuz, Los Serranos, el Caroche, los valles de Ayora y de Montesa.

c) En la provincia de Alicante, las Sierras de La Marina, los Valles de Pego y, en menor medida, la Hoya y Valles de Alcoy.

En cambio, y con agudo contraste, son zonas de fuerte inmigración las siguientes comarcas:

a) La Plana de Castellón, especialmente la Baja, y los Distritos de Vinaroz y Benicarló, excluida la Tinença de Benifassà. [39]

b) El Área Metropolitana de Valencia, con sus subcomarcas de la Huerta, Pla de Quart, Albufera y sus aledañas, Peranxisa y Camp de Llíria. En mucha menor medida, la Huerta de Gandía, el Bajo Palancia o Campo de Sagunto y la Ribera Baja del Júcar.

c) El Campo de Alicante y la Hoya de Castalla, el Campo de Elche, el Valle del Vinalopó y la Marina litoral.

\footnotetext{
${ }^{2}$ Para la delimitación de las comarcas manejadas en este trabajo, vid. Pérez Puchal, 1979, pp. 35-47, o en la trad. valenciana 1980 , pp. 58-69.
} 
En cambio, todas las demás comarcas son de migración neta muy débil, en un sentido o en otro. Así, la Ribera de Torreblanca, el Alcalatén, la Ribera del Turia, la Alta del Júcar, Játiva-La Costera, el Distrito de Ontinyent, la Valldigna, la Canal de Jijona y el Bajo Segura arrojan pequeño saldo positivo, en tanto que la Meseta de Requena-Utiel, el Corredor de Banyeres-Biar y el Distrito de Albaida (o parte oriental de su Valle) lo presentan débilmente negativo.

El estudio de la natalidad diferencial según el promedio de 1975-6 (Apéndice II), comparado con el hecho con los promedios de 1960-5 (Pérez Puchal, 1976, pp. 116-118) muestra, en general, bajas en la natalidad en casi todas las comarcas, pero respecto a las disparidades entre unas y otras no hay más variación que, si acaso, una acentuación más marcada. Actualmente, conviene distinguir entre la que, por convención, puede estimarse en la región valenciana como natalidad alta, del 19 por 1.000 y más, la natalidad intermedia, entre el 15 y el 18 por 1.000 , y la natalidad baja, inferior al 15 por 1.000 . Y aún podría separarse el grupo de comarcas con menos del 12 por 1.000 e índices inferiores a los de mortalidad, en donde el declive de la natalidad es ya irreversible y sólo una fuerte repoblación de jóvenes podría evitar la de otro modo irremediable desertización demográfica a no muy largo plazo.

Para esta clasificación se ha tenido en cuenta que el índice de natalidad española en dicho promedio es de $18^{\prime} 93$ por 1.000 , es decir, tomando como alta para Valencia lo que es natalidad media de España.

Pues bien, la natalidad alta la tienen el Campo de Elche, que da el máximo valenciano con el 23'25 por 1.000, el Campo de Alicante, el Vinalopó, la Hoya de Castalla y el Bajo Segura, en la provincia del sur. En la provincia media, el Área Metropolitana de Valencia, con un 20'5 por 1.000 (y particularmente el Pla de Quart, de máxima inmigración, que alcanza el 23 por 1.000), el valle de Albaida (por el distrito de Ontinyent que sube al 21 por 1.000) y la Huerta de Gandía. En la provincia septentrional, La Plana de Castellón. Obsérvese que, salvo el Bajo Segura, son las comarcas de máxima inmigración y, por tanto, las de composición más joven de su población. También Játiva-La Costera tiene un índice límite del 19 por 1.000.

La natalidad intermedia, entre el 15 y el 18 por 1.000 , ambos inclusive, aparece en la Plana de Vinaroz-Benicarló, en el Camp de Llíria y Ribera [40] del Turia, en el Bajo Palancia, en las Riberas alta y baja del Júcar, en el Valle de Montesa, en La Valldigna y, ya en el límite del 15 por 1.000 , en la Meseta de Requena-Utiel y la Hoya de Buñol. En la provincia meridional, la Hoya y Valles de Alcoy y la Marina septentrional o Marquesado de Denia.

La natalidad baja, entre el 15 y el 12 por 1.000, siempre que siga siendo superior al índice de mortalidad, se da sólo en algunas comarcas de la provincia de Alicante: la Marina meridional costera, la Canal de Jijona y el Corredor de BanyeresBiar. Dentro de estos límites, pero siendo ya inferiores a los índices de mortalidad y con decrecimiento vegetativo, están Los Serranos y el Valle de Ayora, en el interior de la Provincia de Valencia. Por último, las comarcas con índices inferiores al 12 por 1.000 y también con decrecimiento vegetativo son todas las del interior de la Provincia de Castellón, es decir, los Puertos de Morella (con la Tinença de Benifassà), el Alto y Bajo Maestrazgo, el Pla de l'Arc-Ribera de Torreblanca, el Alto Mijares y el Alto Palancia. En la provincia de Valencia, el Rincón de Ademuz (que con el Alto Mijares llega al mínimo índice, inferior al 8 por 1.000), las Gargantas del Júcar o Caroig y la Canal de Navarrés-Enguera. En la provincia de Alicante, sólo las Sierras de la Marina. Naturalmente, todos los índices de mortalidad son muy altos, dado el avanzado envejecimiento de la población. 
Hay una correspondencia muy estrecha entre la mortalidad alta, por encima del 12 por 1.000 (llegando en algunas comarcas al 15), con las de natalidad baja: y entre las de mortalidad baja (inferior al 9 por 1.000) y las de natalidad alta. Así como entre las de mortalidad intermedia (entre 9 y 12 por 1.000) y las de natalidad intermedia. La correlación es casi perfecta porque traduce sobre todo la composición por edades de las respectivas poblaciones, alterada por los intensos movimientos migratorios de los últimos treinta años.

Comparando los índices brutos de natalidad y mortalidad correspondientes a las distintas comarcas, obtenidos del promedio 1975-1976, con los índices promedios 1960-1965 de las mismas comarcas, puede verse que, aunque para el conjunto valenciano son prácticamente los mismos, puesto que el descenso mide solamente seis o siete décimas (lo que en crecimiento vegetativo se traduce sólo en 2 centésimas), en natalidad hay una serie de comarcas con descensos muy sensibles. Únicamente hay dos, la Ribera del Turia y la Ribera Baja del Júcar (ambas inmediatas al Área Metropolitana), así como la Hoya de Castalla, con elevaciones sustanciales de la natalidad; unas pocas más (Vinaroz-Benicarló, Campo de Llíria, Bajo Palancia, Ribera Alta del Júcar, Valles de Montesa y Albaida, Corredor de Banyeres y Campo de Elche) mantienen los mismos niveles, en tanto que La Plana de Castellón [41] y el Área Metropolitana de Valencia presentan un descenso de medio punto. Las demás comarcas tienen caídas más notables. Con esto los índices brutos de mortalidad han descendido allí donde la natalidad o la inmigración (o ambas a la vez) han rejuvenecido la población, como ocurre en La Plana, Área Metropolitana, Campo de Alicante, Campo de Elche (con la mortalidad más baja, 6’3 por 1.000), La Marina meridional, Hoya de Castalla y Corredor de Banyeres; o bien han permanecido invariables, como en casi todas las demás comarcas de Alicante, salvo las Sierras de La Marina, única de la provincia que ha visto elevarse considerablemente su mortalidad. En las comarcas no citadas de las otras dos provincias, el envejecimiento progresivo de su potencial demográfico ha hecho subir los índices, de modo que sólo la Plana de Vinaroz y el Pla de L'Arc-Torreblanca, en la provincia de Castellón, y la Ribera del Turia y sur de la provincia de Valencia (Huerta de Gandía, Valldigna, Valle de Albaida) mantienen estables sus índices brutos.

En su consecuencia, mientras que en el quinquenio inicial de los años sesenta sólo tres comarcas (Bajo Maestrazgo, Rincón de Ademuz y Sierras de La Marina) tenían decrecimiento natural, en 1975-6 el crecimiento vegetativo negativo se ha extendido a nueve comarcas más de las provincias de Castellón (Puertos de Morella, Alto Maestrazgo, Pla de l'Arc, Alto Mijares y Palancia) y de Valencia (Los Serranos, Valle de Ayora, Caroche y Canal de Navarrés). Por contraste, los crecimientos vegetativos superiores son, por este orden, los del Campo de Elche (1'69\%), Campo de Alicante, Hoya de Castalla y Área Metropolitana de Valencia. Un poco por encima del 1\% anual están también el Vinalopó, el Bajo Segura, el Valle de Albaida y La Plana de Castellón.

A la luz de estos índices, es fácil ver la relación estrecha entre fecundidad y natalidad, migración, estructura por edades e industrialización. Y algo análogo podría decirse de la mortalidad, al menos contemplada en la relación defunciones/ población total.

\section{CONCLUSIÓN}


Pese a las reservas que hoy suscita el esquema de Stolniz (Caldwell, passim; Eberstadt, p. 240), en toda transición demográfica hay una fase que es la más significativa o determinante: aquélla en que la mortalidad y la natalidad recorren los niveles intermedios del 20 al 12 por 1.000 en los óbitos y del 30 al 20 por 1.000 en los nacimientos. Niveles que de suyo son transitorios, porque no pueden darse ni en sociedades que no controlen en absoluto su estado sanitario y su fecundidad, ni en sociedades que las controlen en mayor o menor medida, pero con extensión general. Por consiguiente, son niveles que, con más o menos duración [42] y con más o menos ventaja temporal de la mortalidad, indican que el control de una y otra se va difundiendo hasta que, finalmente afirmado, desemboque en otra situación de equilibrio y de crecimiento moderado de la población. O por lo menos debería darlo en un orden, digamos natural. La mayor o menor anticipación del descenso de la mortalidad es lo que mide la mayor o menor explosión del crecimiento.

En España esa fase significativa se ha producido, retrasada con relación a la Europa noroccidental, durante el medio siglo que va de 1920 a 1970 y con un aumento del ritmo de crecimiento templado por la emigración exterior (García Fernández, passim). En la región valenciana, se adelantó ligeramente y su curso fue mucho más rápido, ocupando el tercio de siglo que va de 1912 a 1945, sin gran desajuste entre nacimientos y defunciones, por lo que la explosión demográfica sólo se verificó después de la transición y a cuenta, más que del incremento vegetativo, de la fuerte inmigración neta que el desarrollo ocasionó durante los años 60 y 70. Esa inmigración causó un marcado efecto sobre la fecundidad, al rejuvenecer la población. Hasta tal punto, que ha sido la inmigración neta la que explica, casi exclusivamente, las diferencias que, en natalidad y mortalidad, crecimiento o decrecimiento, se producen en las distintas comarcas de la región.

Como la mortalidad no puede bajar mucho más y, por el contrario, tenderá a subir a causa del progresivo envejecimiento, y eso tanto en la esfera nacional como regional, es evidente que el porvenir de nuestro país depende de la fecundidad y de cuantos factores la afecten, entre ellos la migración; pero también de otros, como la participación de la mujer en el trabajo, así como la política, no ya demográfica, sino la que indirecta y mediatamente modifica la fecundidad y que propugnan algunas corrientes de opinión bajo la capa del progreso social (no siempre bien entendido) y de la liberación de la mujer (a veces mal encaminada). Políticas estas que amenazan alterar el delicado equilibrio que el orden natural está imponiendo poco a poco en el mundo.

En efecto, de siempre vida y muerte han tendido a equilibrarse. Como en el poema de Lucrecio sobre la Naturaleza o en los sombríos versos de Whitman que sirven de epígrafe a estas páginas, los vagidos de los recién nacidos han sofocado los llantos funerarios y «el sollozante fluir de la vida» se ha contrapuesto al «catafalco mortuorio». De modo que, a lo largo de la Historia, cuando epidemias y hambres diezmaban la población, pronto la multiplicación recuperaba las pérdidas $\mathrm{y}$, cuando los progresos tecnológicos y sociales reducían el hambre o la subnutrición y, al aumentar los recursos, determinaban gran incremento demográfico, los frenos positivos a que se refería Malthus restablecían el equilibrio a un nivel numéricamente superior, pero adecuado a la relación [43] población /recursos. Modernamente, la ciencia y la técnica actual han hecho crecer prodigiosamente la capacidad productiva de recursos económicos y subsistencias y reducido la mortalidad a tal punto que han anulado prácticamente los frenos positivos $\mathrm{y}$, aun subalimentadas, las masas humanas pueden seguir viviendo y reproduciéndose. La 
consecuencia es la formidable explosión demográfica que está experimentando el llamado Tercer Mundo, en tanto que Europa y los países desarrollados, con más tiempo y acompasamiento en su evolución, han conseguido restablecer el equilibrio sobre la base de recortar paulatinamente su fecundidad. Que el Tercer Mundo seguirá análogo camino lo demuestra el declive de la fecundidad que han empezado a experimentar sus diversos países desde 1965 y sobre todo desde 1970, aunque más perezosamente en África, que es justamente el menos poblado de los continentes (Eberstadt, passim). Es decir, que todo hace prever que, una vez asimilada la superior cantidad de pobladores que el mundo puede sostener, el crecimiento volverá a estabilizarse, esta vez con mortalidades y natalidades sumamente bajas.

Ahora bien, en los países desarrollados el control de la natalidad ha llegado a un nivel tal que amenaza la propia supervivencia de sus pueblos, especialmente en la Europa noroccidental, central y oriental. La extensión del aborto que, allá donde se aplica y favorece, ha demostrado ser el arma más eficaz contra la natalidad, así como, en nuestro mundo occidental, la afirmación de una mentalidad en favor de la libertad sexual (que no puede concebirse sin la contraconcepción y el aborto) o el prestigio de que se quiere revestir en ciertos círculos a la homosexualidad, está haciendo estragos; resulta más up to date y a la última la unión libre que el matrimonio, al que se reputa de burgués y aburrido. La posibilidad de averiguar el sexo del hijo esperado está actuando con una terrible discriminación por sexo en la India, donde, según la Prensa ha difundido recientemente, de cada tres mujeres grávidas a las que se ha diagnosticado feto femenino, dos han abortado; excusado es decir los efectos demográficos y sociales que esta descompensación de sexos puede llegar a producir. Ciertamente, la ética natural y las costumbres de las masas hacen que muchas de estas circunstancias resbalen sin calar profundamente en ellas; es elocuente el repetido fracaso o, al menos, los bajos resultados de las políticas antinatalistas llevadas a cabo por las Naciones Unidas y el éxito, en cambio, en la reducción de la fecundidad, que han tenido las mejoras económicas, educativas, culturales y sociales que conforman una mentalidad distinta de la tradicional, sobre todo en las mujeres. Pero lo que está ocurriendo en algunos puntos de Europa avisa claramente del peligro que puede originar la manipulación técnica y política de las fuentes de la vida cuando [44] se desconecta de la ética, de la propia tendencia natural de las sociedades a equilibrarse e incluso de la mera previsión.

En España, hasta 1980 el juego de natalidad y fecundidad se ha ido acompasando de manera que, dentro de su carrera descendente, ha permitido un crecimiento moderado e idóneo a nuestras circunstancias económicas y sociales, a lo que ha contribuido también la emigración neta exterior. Pero la natalidad, siguiendo las pautas europeas, está bajando tanto que, de seguir así, se pondría en peligro nuestra propia subsistencia como pueblo. La inversión del saldo migratorio exterior de estos últimos años, producida por el retorno de los emigrados e interrupción de los movimientos de salida, mantiene el crecimiento demográfico, pero nuestro índice de reproducción parece haber caído por debajo de 1. La difusión oficial (probablemente bien intencionada) y establecimiento de dispensarios de planificación familiar, como si fuéramos un pueblo subdesarrollado e inculto, no hará más que agravar la situación, si no cae en el ridículo, dada nuestra idiosincrasia y nivel cultural y económico, y la extraña confusión que se hace de planificación familiar y combate de enfermedades venéreas.

Es de desear que sepamos mantener, como colectividad, una fecundidad acorde con la mortalidad, que evite crecimientos desbordantes, pero que asegura una 
estabilidad e incluso un crecimiento lento, imprescindible para sostener una sociedad viva, sana, abierta a todas las iniciativas juveniles, con una cuota proporcionada de ancianos y jubilados, impulsada por una juventud permanentemente renovada y sostenedora de una economía en progreso y asimiladora de las técnicas nuevas, capaz de evolucionar sin pausa (Sauvy, 1971, passim). De lo contrario, no habrían de transcurrir muchos decenios sin que, al considerar nuestras fuerzas vitales y fundamentos demográficos, no tuviéramos que repetir el lamento de Quevedo, al contemplar «los muros de la patria» nuestra,

si un tiempo fuertes, ya desmoronados.

Departamento de Geografía Humana

Universidad de Valencia

[45]

\section{FUENTES ESTADÍSTICAS}

1. Instituto Nacional de Estadística: Censos de Población. Tomos decenales desde 1900 hasta el avance del Censo de 1981.

2. Ibidem: Movimiento natural de la población española. Volúmenes anuales desde 1922 a 1978. Sólo desde 1975 (con tres tomos cada año, divididos en fascículos) figuran las clasificaciones de nacimientos por edades de las madres en las distintas provincias.

3. Ibidem: Anuarios Estadísticos. Tomos anuales hasta 1982.

4. Ibidem: Características de la población española deducidas del Padrón Municipal de Habitantes, según la inscripción realizada el 31 de diciembre de 1975. Dos tomos, divididos en fascículos regionales. (Madrid, Ministerio de Economía, 1979).

5. Ibidem: Tasas netas de reproducción. Madrid, Servicio de Investigaciones demográficas y sociales, 1966. 44 págs. más III láms.

6. Ibidem: Encuesta de fecundidad, (Diciembre 1977). Metodología y resultados. Madrid, Ministerio de Economía. 1978. 228 págs.

7. Ibidem: Tablas de mortalidad provinciales (1969-1972). Año 1970. Madrid, Ministerio de Economía, 1978. 100 págs.

8. Ibidem: Migraciones interiores en España. Quinquenio 1971-1975. Madrid, Ministerio de Economía, 1978. 152 págs. más 22 mapas.

9. Ibidem: Encuesta de población activa. Madrid, Ministerio de Economía, 1979.

10. Ibidem: Evolución de la población española en el período 1961-1978. Madrid, Ministerio de Economía, 1980. 182 págs.

11. United Nations: Demographic Yearbook. New York, Statistical Office of the United Nations, tomos anuales.

\section{BIBLIOGRAFÍA}


(1) Aird, John S.: «Fertility decline in China». Apud Eberstadt, Nick: Fertility decline in the less developed countries, New York, Praeger, 1981, págs. 119-227.

(2) Barbancho, Alfonso G.: Población, empleo, paro. Madrid, Pirámide, 1982. 158 págs. 33 mapas y gráficos.

(3) Ibidem. Las migraciones interiores españolas. Estudio cuantitativo desde 1900. Madrid, Instituto de Desarrollado Económico, 1967.

(4) Ibidem: Las migraciones interiores españolas en 1961-1970. Madrid, Instituto de Estudios Económicos, 1975.

(5) Brown, Richard D.: Modernization: The Transformation of American Life, 1600-1865. New York, Norton, 1976.

(6) Burriel de Orueta, Eugenio: Demografía de la huerta de Valencia, zona sur. Madrid, Instituto Elcano CSIC, 1971. 106 págs.

(7) Ibidem: «Evolución moderna de la población de Canarias». Estudios Geográficos, núms. 138-9 (1975), págs. 157-197. 2 mapas y gráficos.

(8) Cabo, Ángel: «Evolución demográfica de Valencia y su provincia». Estudios Geográficos, nº 94 (1964), págs. 96-101.

(9) Caldwell, John C.: «Toward a restatement of demographic transition Theory». Population and Development Review, 1976: 2 (3 y 4), 321-366.

(10) Campo, Salustiano del: Análisis de la población de España. Barcelona, Ariel. 1972. 192 págs. 4 mapas y gráficos.

(11) Ibidem: La política demográfica en España. Madrid, Edit. Cuadernos para el Diálogo, 1974. 238 págs. [46]

(12) el, Horacio: «Los estudios acerca de las migraciones interiores en España». Revista de Geografía de la Universidad de Barcelona, 1967, págs. 77-101.

(13) ark, Colin: El aumento de la población. Madrid, EMESA, 1972. 228 págs.

(14) ourtot, Roland: "Geografía de las migraciones de trabajadores en la provincia de Valencia». Trad. Antonio López Gómez. Estudios Geográficos, núms. 112-113 (1968), págs 99-526.

(15) Eberstadt, Nick: Fertility decline in the less developed countries. New York, Praeger Scientific, 1981. 370 págs.

(16) Estébanez Álvarez, J. - Puyol Antolín, R.: «Los movimientos migratorios españoles durante el decenio 1961-1970». Geographica, no 2 (1973), págs. 105-142.

(17) Ferrer Regales, Manuel: La población, entre la vida y la muerte. Madrid, Edit. Magisterio Español, 1975, 158 págs.

(18) Ferrer Regales, M. - Navarro, A. - Entremont, A.: Las políticas demográficas. Pamplona EUNSA, 1975. 206 págs.

(19) Frisch, Rose E.: «Population, nutrition and fecundity: significance for interpretation of changes in fertility». Apud Eberstadt, Nick, op. cit. págs. 319-336.

(20) García Ballesteros, Aurora: «La fecundidad de la población española en 1970. Aplicación de un nuevo método demográfico». Revista Internacional de Sociología, CSIC, núms. 18-20 (1976), págs. 49-62 más 1 encarte. 2 mapas.

(21) Ibidem: Crecimiento y problemas de la población mundial. Madrid, Salvat, 1982, 64 págs.

(22) García Fernández, Jesús: La emigración exterior de España. Barcelona, Ariel, 1965. 302 págs. 11 mapas. 
(23) Gozálvez Pérez, Vicente: «La población del País Valenciano según el Censo de 1981 ». Cuadernos de Geografía de la Universidad de Valencia, nº 29 (1981). 1 mapa.

(24) Glass, D.V. - Eversley, D.E.C. (dirs). Population in History. Essays in Historical Demography. London, Edward Arnold, 1965. 692 págs.

(25) Jones, Huw R.: A population Geography. London, Harper and Row, 1981. 330 págs. 93 mapas y gráficos.

(26) Lacomba, Juan Antonio: «Notas sobre la demografía española durante el primer tercio del siglo XX». Apud Ensayos sobre el siglo XX español. Madrid, Cuadernos para el Diálogo, 1972, págs. 31-58.

(27) López Gómez, Antonio: «La estructura demográfica de Valencia». Saitabi, t. XI (1961), págs. 118-143.

(28) Ibidem: Geografia de les terres valencianes. València, Departament de Geografia de la Universitat, 1977. 264 págs. más XXIV lám. 40 mapas y gráficos.

(29) Maluquer i Sostres, Joaquim: Població i societat a l'àrea catalana. Barcelona, Edit. AC, 1965, 188 págs.

(30) Mamdani, Mamood: The myth of Population Control, New York, Monthly Review, 1972.

(31) Nadal, Jordi: La población española (siglos XVI a XX). Barcelona, Ariel, 1976. $4^{\mathrm{a}}$ ed. 286 págs. 27 gráficos.

(32) Pérez Puchal, Pedro: Geografia de la població valenciana, València, L’Estel, 1976. 170 págs. 21 mapas y gráficos.

(33) Ibidem: «La comarcalización del territorio valenciano». Estudios Geográficos CSIC, $\mathrm{n}^{\circ} 154$ (1979), págs. 25-49. 1 mapa. Hay trad. valenciana en Taula redona sobre la comarcalització al País Valencià, t. I, págs. 49-72.

(34) Ibidem: La natalidad en España. Valencia, Secretariado de Publicaciones de la Universidad, 1980. 70 págs. 9 mapas y gráficos.

(35) Petersen, William: «American efforts to reduce the fertility of less developed countries». Apud, Eberstadt Nick, op. cit. págs. 337-362. [47]

(36) Ros Jimeno, José: «El decrecimiento de la natalidad y sus causas». Estudios Demográficos, CSIC, t. 1 (1945), págs. 27-100.

(37) Rosselló Verger, Vicente $\mathbf{M}^{\mathbf{a}}$ : «Dinámica poblacional en las Canarias orientales (1960-1975). Estudios Geográficos, n 152 (1978), págs. 267-284.

(38) Ruiz Almansa, Javier: "Reproductividad neta de las provincias y regiones de España». Boletín de Estadística, $\mathrm{n}^{\circ} 16$.

(39) Sáez, Armand: «La fécondité en Espagne depuis le début du siècle». Population, Revue de L'INED, 1979, págs. 1007-1021. 5 gráficos.

(40) Sánchez Albornoz, Nicolás: «La modernización demográfica. La transformación del ciclo vital anual 1863-1960». Jalones de la modernización en España. Barcelona, Ariel, 1975, págs. 149-180.

(41) Sauvy, Alfred: El problema de la población en el mundo de Malthus a Mao Tse-Tung. Trad. J. Fontanilla. Madrid, Aguilar, 1961. 364 págs.

(42) Ibidem: Malthus et les deux Marx. Le problème de la faim et de la guerre dans le monde. París, Denoël, 1963. 298 págs. Hay trad. española: El hambre, la guerra y el control de la natalidad. Barcelona, Edit. Vicens-Vives, 1965.

(43) Ibidem: La rebelión de los jóvenes. Trad. C. Manzano. Barcelona, DOPESA, 1971. 248 págs.

(44) Scientific American: La población humana. Barcelona, Labor, 1976. 325 págs. 93 mapas y gráficos. 
(45) Stolniz, G. J.: «The demographic Transition: from high lo low birth rates and death rates». Apud Demko, George - Rose, Harold - Schnell, George: Population Geography: a reader. New York, Mc. Graw-Hill, 1970, págs. 71-78.

$$
\begin{gathered}
\text { APÉNDICE I } \\
\text { ÍNDICES BRUTOS DE NATALIDAD Y MORTALIDAD. POR MIL }
\end{gathered}
$$

Años Provincia Alicante Provincia Castellón Provincia Valencia

\begin{tabular}{|c|c|c|c|c|c|c|}
\hline 1901-1905 & $33^{\prime} 67$ & $22^{\prime} 66$ & 33 '90 & $23^{\prime} 60$ & $35 ’ 24$ & $24^{\prime} 80$ \\
\hline 1906-1910 & $29 ’ 40$ & $21 ' 50$ & $30 ’ 39$ & $21^{\prime} 06$ & $32 ’ 79$ & 21'91 \\
\hline 1911-1915 & $24^{\prime} 13$ & 19'33 & $26^{\prime} 20$ & 20’11 & $27^{\prime} 99$ & $19^{\prime} 82$ \\
\hline 1916-1920 & $24^{\prime} 83$ & $22 ’ 44$ & $23 ’ 15$ & $21^{\prime} 79$ & $25^{\prime} 28$ & $22^{\prime} 63$ \\
\hline $1921-1925$ & $27^{\prime} 66$ & 19'39 & $24^{\prime} 38$ & $18^{\prime} 68$ & $25^{\prime} 79$ & $18^{\prime} 60$ \\
\hline 1926-1930 & $26 ' 12$ & $17^{\prime} 49$ & $21 ' 87$ & $17^{\prime} 22$ & $24 ’ 24$ & $17 ' 25$ \\
\hline 1931-1935 & $23^{\prime} 80$ & $15^{\prime} 93$ & 19’99 & $15^{\prime} 97$ & $21^{\prime} 87$ & $15^{\prime} 41$ \\
\hline 1936-1940 & $21^{\prime} 70$ & $18 ' 26$ & $15^{\prime} 73$ & $20^{\prime} 44$ & $19^{\prime} 23$ & $18^{\prime} 29$ \\
\hline 1941-1945 & $19 ' 15$ & 13 '41 & $16^{\prime} 51$ & $14 ’ 57$ & $17 ’ 24$ & 13 '11 \\
\hline $1946-1950$ & $19 ' 49$ & $11 ' 12$ & $16 ’ 39$ & $12 ' 52$ & $17^{\prime} 43$ & $11 ' 59$ \\
\hline $1951-1955$ & $18^{\prime} 41$ & $10 ’ 37$ & $15^{\prime} 67$ & $11^{\prime} 67$ & $17^{\prime} 30$ & $10^{\prime} 27$ \\
\hline $1956-1960$ & $20^{\prime} 52$ & 9'70 & $15^{\prime} 78$ & $11 ' 21$ & $18^{\prime} 40$ & $10 ’ 01$ \\
\hline 1961-1965 & $21^{\prime} 90$ & 9’70 & $16^{\prime} 90$ & $10^{\prime} 82$ & $19 ’ 90$ & 9'60 \\
\hline 1966-1970 & $22^{\prime} 06$ & 9'24 & $16 ’ 98$ & $10 ’ 89$ & $20 ’ 36$ & 9'58 \\
\hline 1971-1974 & $20 ’ 95$ & 8'93 & $16^{\prime} 76$ & $10 ’ 96$ & $19 ’ 35$ & 9’31 \\
\hline $\begin{array}{l}1975-1976 \\
{[48]}\end{array}$ & $19^{\prime} 72$ & $8 ' 37$ & $17^{\prime} 17$ & $10^{\prime} 22$ & $19^{\prime} 36$ & 9’03 \\
\hline
\end{tabular}

Promedio Natalidad Mortalidad NatalidadMortalidad Natalidad Mortalidad 


\begin{tabular}{|c|c|c|c|c|c|}
\hline Comarca & $\%$ & \% & $\%$ & $\%$ & \% \\
\hline Puertos de Morella & 997 & 1350 & 035 & .315 & .280 \\
\hline Alto Moestrazgo (Pofagol.) & $10 \cdot 57$ & 1375 & .031 & -235 & $-2^{\prime} 04$ \\
\hline Alcalatén & $12^{\prime} 86$ & $10^{\prime} 11$ & 027 & 082 & 065 \\
\hline A/to Moestrargo & $11 ' 32$ & 1227 & .096 & 139 & -044 \\
\hline Distrito Vinaroz & 1760 & 1212 & $0^{\prime} 55$ & 299 & 244 \\
\hline Distrito de Benicarlo & 1821 & 1055 & 0,76 & 298 & 217 \\
\hline $\begin{array}{l}\text { Bajo Moestrazgo } \\
\text { (dist. S. Mateo) }\end{array}$ & & & & & $\gamma<4$ \\
\hline $\begin{array}{l}\text { Idist. S. Mateol } \\
\text { Pla de r'Arc y }\end{array}$ & 970 & $15^{\prime} 65$ & -058 & 103 & .044 \\
\hline Ribera Torreblanca & $11 \% 40$ & 1219 & $-0^{\prime} 12$ & 034 & $0^{\prime} 46$ \\
\hline Eajo Moestrezgo & 1441 & 1265 & 018 & $1 / 31$ & 113 \\
\hline Alto Mijares & 744 & 1520 & .077 & -370 & 289 \\
\hline Alto Palancia & $11^{\prime} 86$ & 1382 & $-0^{\prime} 19$ & $.1 \% 68$ & $-1 / 47$ \\
\hline Plana Baja & 1977 & 891 & 108 & 244 & 136 \\
\hline Piana Alta & 1780 & 826 & 095 & 134 & $0 \% 39$ \\
\hline Espadan & 1850 & 869 & $0 \prime 98$ & 104 & 006 \\
\hline Alana de Costellibn & 1943 & 882 & 106 & 215 & 109 \\
\hline Provincia de Castellion & 1717 & 1022 & $0^{\prime} 69$ & 121 & $0 \leqslant 2$ \\
\hline Rincón de Ademuz & 792 & $14^{\prime} 80$ & .060 & 384 & -320 \\
\hline Los Serranos & $12 \cdot 24$ & $14^{\prime} 86$ & .026 & -378 & -352 \\
\hline Campo de Liria & 1635 & 1093 & 056 & $1 ' 66$ & $1 ' 10$ \\
\hline Ribera del Turia & 1823 & $9^{\prime} 18$ & 090 & 122 & 032 \\
\hline Campo de line & 1704 & $10^{\prime} 42$ & 066 & 140 & 074 \\
\hline Bajo Palancia & 1883 & 910 & 097 & 175 & 078 \\
\hline Campo de Requena & $16: 35$ & 1339 & 029 & -012 & .041 \\
\hline Campo de Utiel & $14^{\prime} 08$ & 1324 & 008 & $-0,65$ & -073 \\
\hline Meserta Requera-Uthel & $15^{\prime} 14$ & 1331 & $0^{\prime} 18$ & -0.41 & .059 \\
\hline Hoye de Buñol idist. Buffoll & 1517 & $10^{\prime} 12$ & $0^{\prime} 50$ & 130 & 080 \\
\hline Peranxisa & 1589 & 1129 & 046 & 165 & 112 \\
\hline Hoya de Buñol & $15 \cdot 58$ & 1079 & 0.48 & 150 & 102 \\
\hline Huerta de Valencia & $20^{\prime} 25$ & 846 & 118 & 255 & 137 \\
\hline Pla de Cuart & 2302 & 662 & $1 ' 64$ & $3^{\prime} 13$ & $1 / 49$ \\
\hline La Albufera & 2004 & 767 & 123 & 296 & 173 \\
\hline La Calderona & 1485 & 1192 & 029 & 106 & 077 \\
\hline Area Metropolitana Valencio & 2049 & 823 & 122 & 263 & 141 \\
\hline Valie de Ayora & 1334 & 1398 & $\gamma 06$ & $1 / 31$ & 125 \\
\hline Gargentas dol Júcat & 1010 & 1055 & .004 & -423 & .419 \\
\hline Enguera-Canal de Navarres & 11193 & 1231 & 003 & 0.15 & $C 12$ \\
\hline El caroche & 1233 & 1281 & .004 & .094 & .990 \\
\hline
\end{tabular}




\section{Comarcs}

Els Alcalans

Distrito de Carlet

Distrito de Alberic

Distrito de Alcira

Ribers Alts del Jicar

Aibera Baja del Jücar

Jativa-La Costera

Valle de Mantesa

Comarca setabense

Huerta de Gandis

La Valldigna

\section{La Safor}

Distito de Ontinyent

Distrito de Albaida

Valle de Albarits

Provincia do Valancia

Valles de Pego

Maxina saptentriona

Marquesado de Denia

Hova y valles de Alcoy

Corredor de Bañeres Biat

Hova de Castalia

Canal de Jijona

Serrania de Alcoy

Marina litcoal

Sierras de la Marina

La Marina

Camoo de Alicante

Alto Vinalopo

Vinalopo Medio

Valle clet Vinatood

Campo de Elche

Bajo Segura

Provincia de Alicante

Rogion valenciana

\begin{tabular}{|c|c|c|c|c|}
\hline $\begin{array}{c}\text { Natalidad } \\
\% \\
\end{array}$ & $\begin{array}{c}\text { Mortalidad } \\
\%\end{array}$ & $\begin{array}{c}\text { Crecim } \\
\text { veget. } \\
\%\end{array}$ & $\begin{array}{c}\text { Crecim } \\
\text { real } \\
\% \\
\end{array}$ & $\begin{array}{c}\text { Migracion } \\
\text { nets } \\
\$\end{array}$ \\
\hline 1377 & 1138 & $0^{\prime} 24$ & 043 & 019 \\
\hline 2010 & 896 & 111 & $1 / 37$ & 026 \\
\hline $15^{\prime} 18$ & 1236 & 028 & 054 & 026 \\
\hline 1710 & 1009 & 070 & $1 \times 18$ & 048 \\
\hline 1725 & 1022 & 070 & 109 & 039 \\
\hline 1802 & $10^{\prime} 87$ & 071 & $1 / 49$ & 078 \\
\hline 1900 & 1036 & $0^{\prime} 86$ & 105 & Ơ19 \\
\hline 1729 & $10^{\prime} 18$ & 071 & .005 & 076 \\
\hline 1871 & $10^{\prime} 33$ & 083 & 086 & 003 \\
\hline 1902 & 974 & $0 \% 93$ & 155 & $0^{\prime} 62$ \\
\hline 1590 & $10^{\prime} 44$ & 054 & 109 & OS5 \\
\hline 1846 & 986 & $0^{\prime} 86$ & 1466 & 060 \\
\hline 20997 & 776 & 132 & 169 & 037 \\
\hline 1791 & $9^{\prime} 48$ & $O_{B A}$ & $0^{\prime} 64$ & 020 \\
\hline 1945 & 861 & $1 / 06$ & 116 & 008 \\
\hline 1936 & 900 & 103 & 184 & 081 \\
\hline 1238 & 1263 & .025 & 213 & 188 \\
\hline 1646 & 1173 & 047 & 315 & 268 \\
\hline 1556 & $11 ' 93$ & $\sigma 36$ & 183 & 147 \\
\hline 1725 & 1085 & $\sigma 64$ & 012 & 076 \\
\hline 1485 & 806 & 067 & 053 & 014 \\
\hline 2071 & 745 & 132 & 375 & 243 \\
\hline $14^{\prime} 01$ & 1079 & 032 & 036 & 004 \\
\hline 1758 & 984 & $0 n$ & 077 & 000 \\
\hline 1775 & 840 & $0^{\prime} 93$ & 800 & 707 \\
\hline 922 & $17^{\prime} 24$ & .000 & .257 & $i n$ \\
\hline 1722 & 895 & 082 & 713 & 631 \\
\hline $22^{0} 08$ & 841 & 136 & 348 & 212 \\
\hline 1980 & 900 & 107 & 167 & $\gamma 60$ \\
\hline 2021 & 825 & I'19 & 228 & 109 \\
\hline 2012 & 843 & 117 & 216 & 099 \\
\hline 2325 & 629 & 169 & 356 & 187 \\
\hline 1992 & 883 & 111 & 1.55 & 044 \\
\hline 1972 & 837 & $1 ' 13$ & 340 & 227 \\
\hline $19^{\prime} 20$ & 896 & 102 & 225 & 123 \\
\hline
\end{tabular}

- El crecimiento real tesulta del incremento anual acumulativo entre 1970 y 1975 


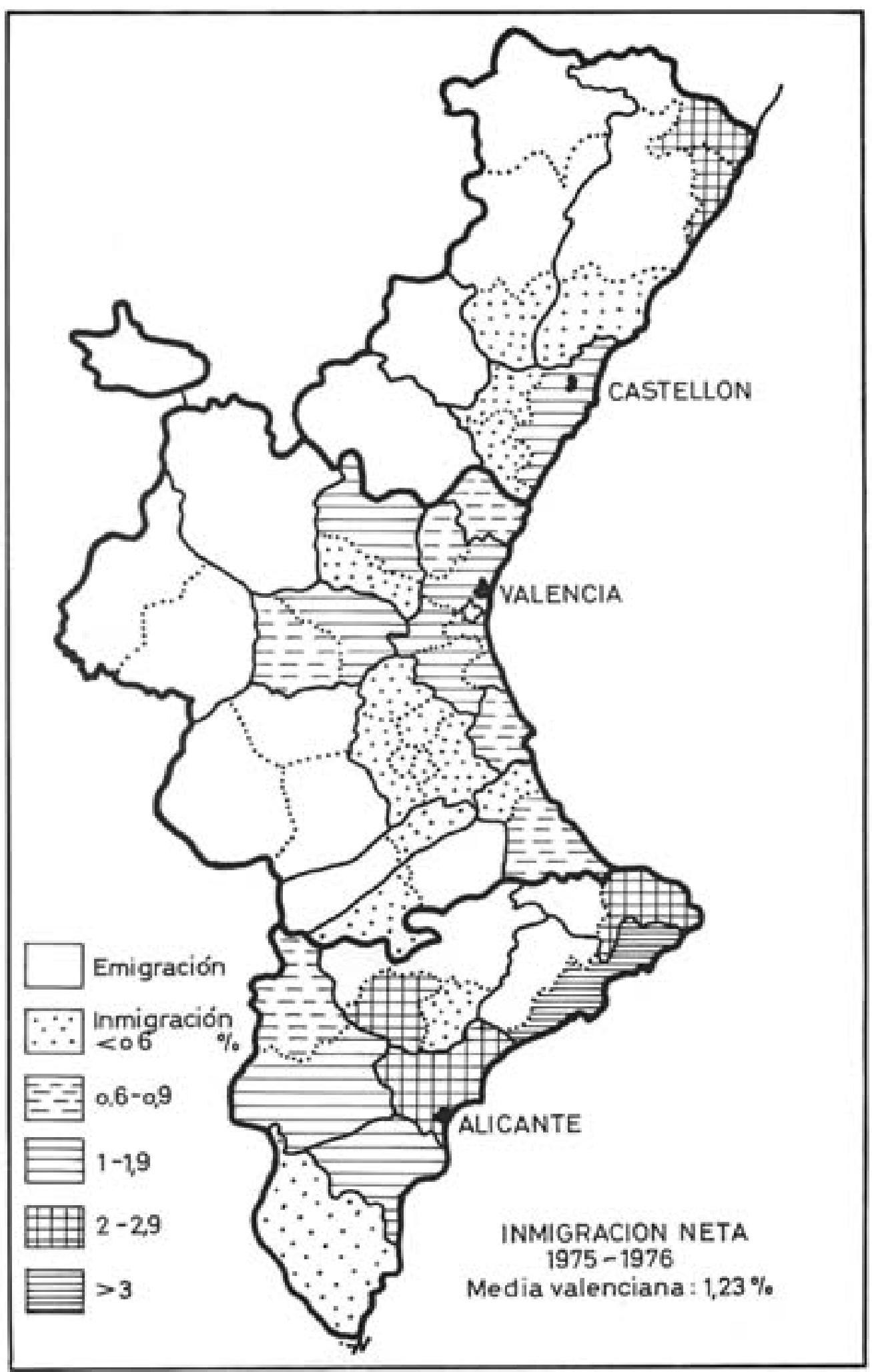




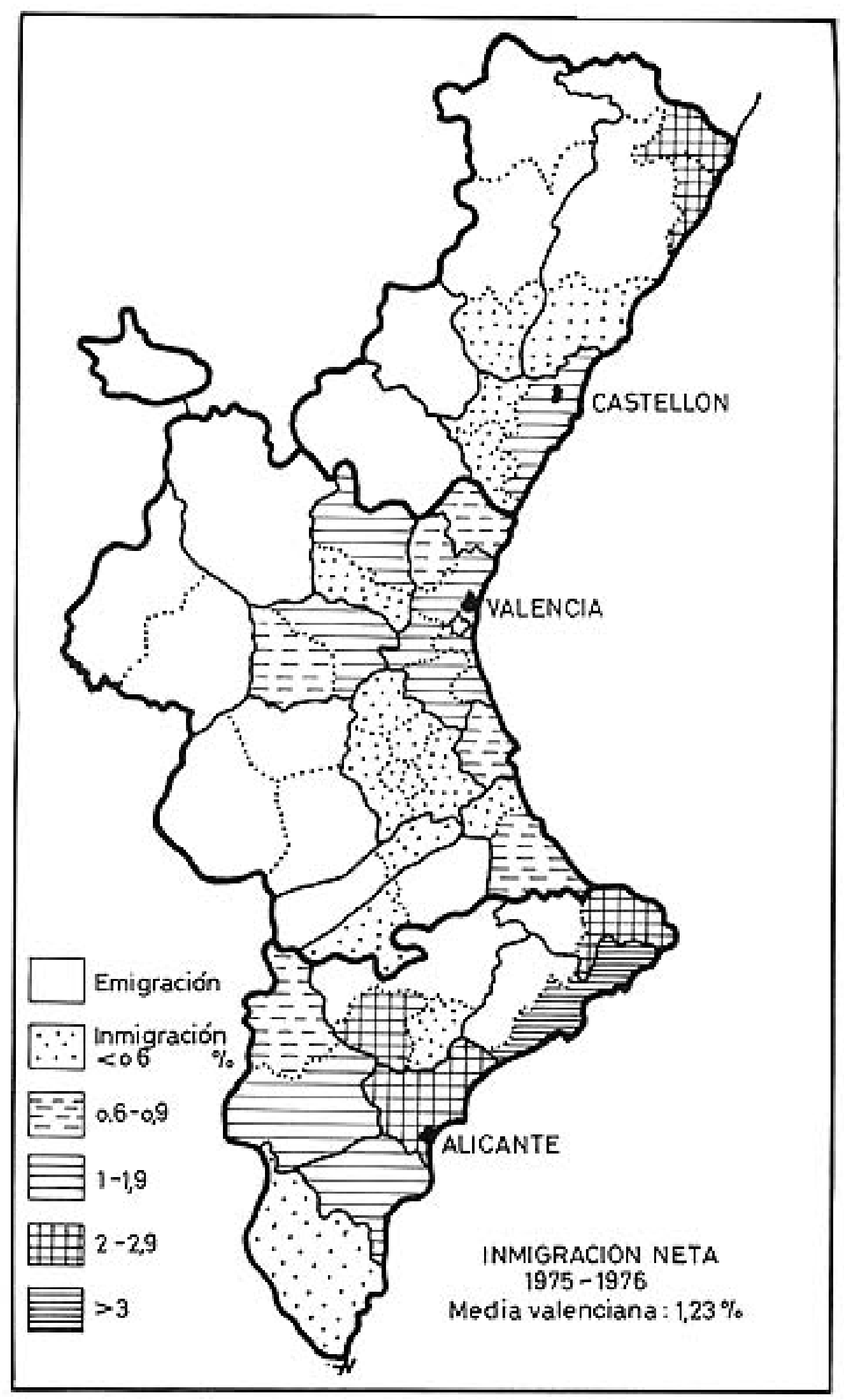

I 


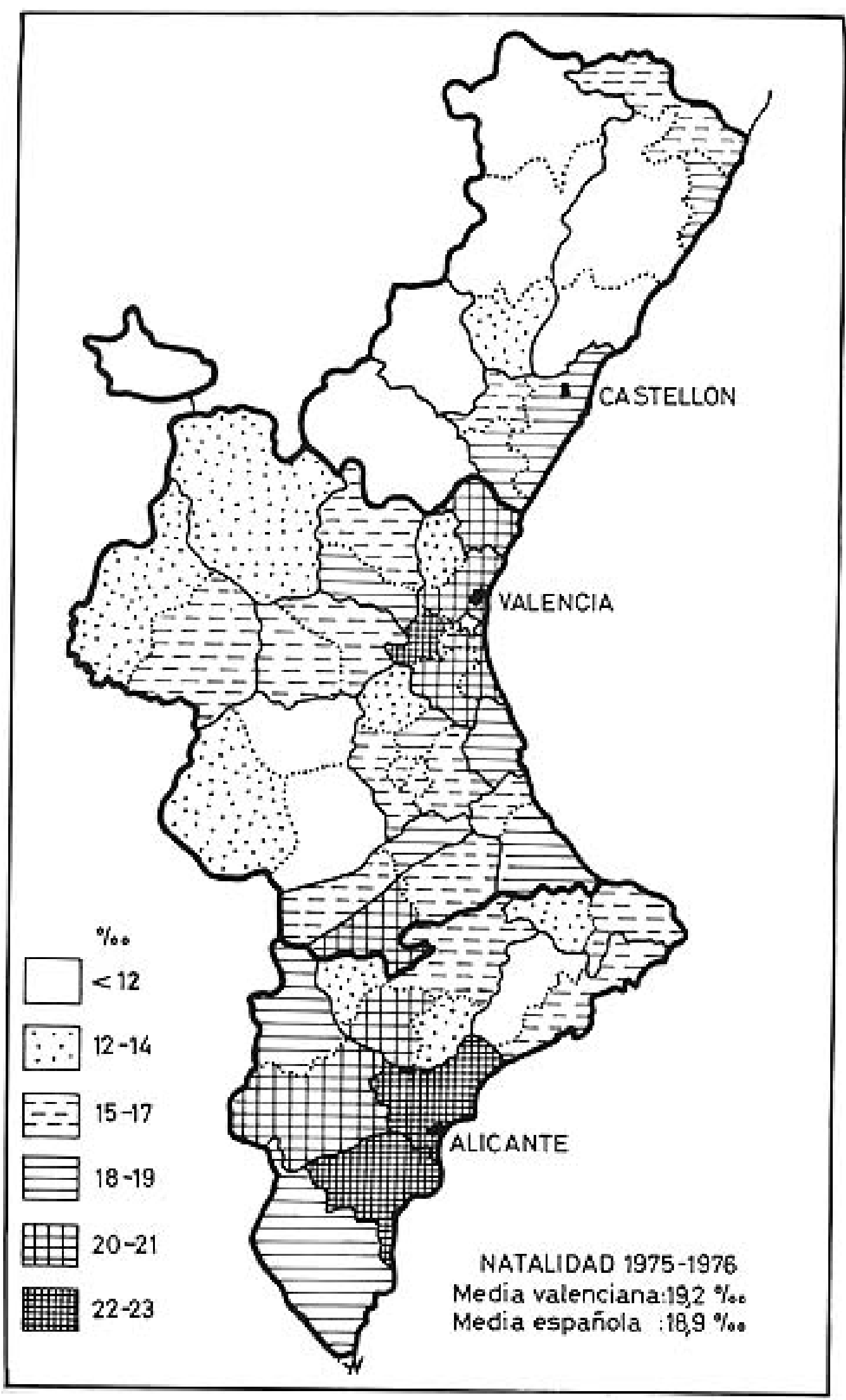




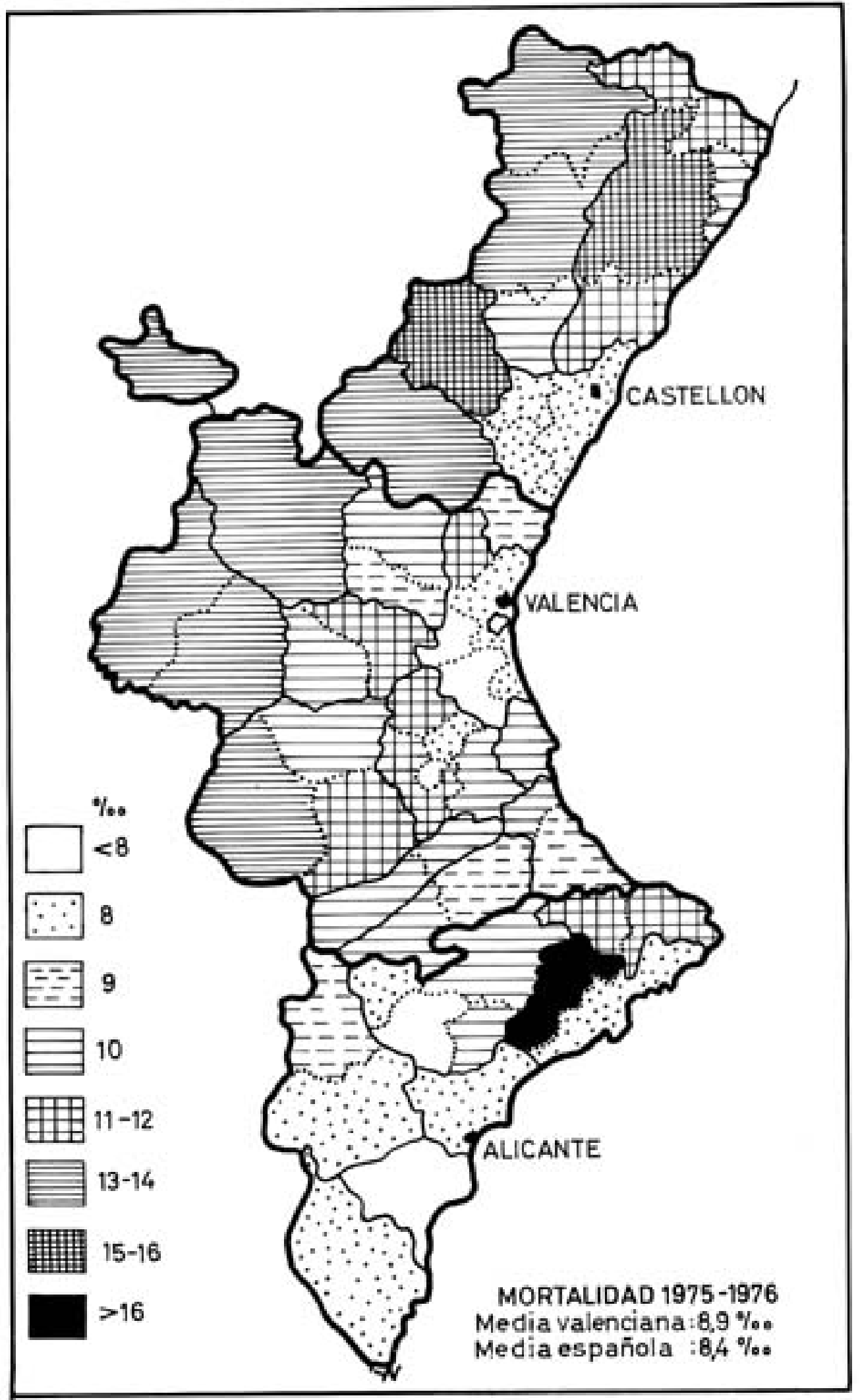

